\title{
The Genetic Basis of FSGS and Steroid-Resistant Nephrosis
}

\author{
By Martin R. Pollak
}

\begin{abstract}
Studies of Mendelian forms of focal segmental glomerulosclerosis (FSGS) and nephrotic syndrome have provided new insights into the mechanism of these diseases. Congenital nephrotic syndrome and familial forms of FSGS form a spectrum of podocyte diseases of varying severity and age of onset. Mutations in both nephrin gene (NPHS1) alleles lead to congenital nephrosis, podocyte foot process effacement, and loss of slit-diaphragm structure. Mutations in both podocin gene (NPHS2) alleles lead to a wide range of human disease, from childhoodonset steroid-resistant FSGS and minimal change disease to adult-onset FSGS. Dominantly inherited mutations in ACTN4, the $\alpha$-actinin-4 gene, can lead to a slowly progressive adult-onset form of FSGS. In addition, FSGS is observed as part of several rare multisystem inherited syndromes. Here we review recent progress in understanding the genetic basis of FSGS in humans.
\end{abstract}

() 2003 Elsevier Inc. All rights reserved.

$\mathbf{T}$ HE ROLE OF GENETIC factors in the development of focal segmental glomerulosclerosis (FSGS) in humans has become increasingly apparent in recent years. Genetic studies also have helped strengthen the notion that glomerular visceral epithelial cell (or podocyte) disorders lead to a spectrum of clinical presentations, from congenital nephrotic syndrome (CNF), to minimal change disease (MCD), and FSGS. Here we review recent progress in the understanding of the role of genetic factors in these related disorders of podocytes.

\section{MENDELIAN DISEASE}

Studies of Mendelian forms of disease have provided (and will continue to provide) some of the most novel insights into the mechanisms of human disease. Clinicians have observed familial aggregation of proteinuric disease for some time, though recognition of familial nephrosis has not been widespread. For over half a century, there have been scattered reports in the medical literature of familial nephrosis. ${ }^{1}$ Four siblings with nephrotic syndrome were described in a 1957 report. $^{2}$ Pathology showed minimal change disease in some children, FSGS in others. The absence of disease in the parents suggested recessive inheritance. Additional scattered reports of both single-generation and multigeneration disease have continued to appear in the case literature. ${ }^{3-8}$ Of course, familial disease need not be inherited-multiple members of a family may be exposed to the same environmental insults. However, recent studies of Mendelian disease have begun to clarify the clinical spectrum of the group of disorders that make up familial FSGS and familial nephrotic syndrome (Table 1). Studies involving genetic manipulations in mice have identified additional genes involved in regulating the normal podocyte phenotype and in the development of FSGS. In the past several years, novel proteins have been identified in 2 childhood forms of nephritic syndrome using purely positional genetic approaches.

\section{GENETICS}

Congenital nephrotic syndrome of the Finnish type, or CNF, is a geographically widespread disease characterized by the development of severe nephrosis in utero and autosomal-recessive inheritance. ${ }^{9}$ Affected neonates have on the order of 20 to $30 \mathrm{~g} / \mathrm{d}$ proteinuria and typically die from complications of the nephrotic syndrome at a young age unless nephrectomy and renal transplantation are performed. Without renal transplantation, mortality is essentially $100 \%$. Typical problems include infection, growth retardation, prematurity, and the development of renal insufficiency. ${ }^{10} \mathrm{CNF}$ presents neonatally but is present prenatally. Parents of CNF infants (and therefore obligate heterozygotes) have no apparent phenotype, though prenatal proteinuria is detectable in a substantial fraction of heterozygotes before birth.

Subsequent to mapping the CNF gene to chromosome $19 \mathrm{q} 13$ by a means of a genome-wide linkage analysis, the CNF gene NPHS1 was cloned by positional methods..$^{11,12}$ NPHS1 spans $26 \mathrm{~kb}$ of genomic DNA and contains 29 exons. ${ }^{13}$ Nephrin, the gene product, is a $185-\mathrm{kd}$ protein containing a fibronectin III-like domain, 8 immunoglobulin $\mathrm{C} 2$ motifs, and a single transmembrane segment. Nephrin localizes to the slit diaphragm in the podo-

From the Renal Division, Brigham and Women's Hospital, 77 Louis Pasteur Ave, Boston, MA.

Address reprint requests to Martin R. Pollak, MD, Renal Division, Brigham and Women's Hospital, 77 Louis Pasteur Ave, Boston, MA 02115. E-mail: mpollak@rics.bwh.harvard.edu

(C) 2003 Elsevier Inc. All rights reserved. 0270-9295/03/2302-0004\$30.00/0

doi:10.1053/snep.2003.50014 
Table 1. Identified Nonsyndromic FSGS/NS Genes

\begin{tabular}{|c|c|c|c|c|c|c|}
\hline Disease & Locus & Inheritance & Gene & Protein & MIM Number* & Study \\
\hline Congenital nephrotic syndrome & $19 q 13.1$ & Autosomal recessive & NPHS1 & Nephrin & 602716 & Kestila et $\mathrm{al}^{12}$ \\
\hline Steroid-resistant-NS & $1 q 25-32$ & Autosomal recessive & NPHS2 & Podocin & 604766 & Boute et $\mathrm{al}^{31}$ \\
\hline FSGS & $19 q 13$ & Autosomal dominant & ACTN4 & $\alpha$-actinin-4 & 604638 & Kaplan et al 44 \\
\hline
\end{tabular}

${ }^{*}$ Mendelian inheritance in man number.

cyte. ${ }^{14-17}$ Nephrin appears to play a role in regulating signaling pathways. ${ }^{18}$ Localization to signaling domains known as lipid rafts has been shown recently. ${ }^{17,19}$

Most of the congenital nephrotic syndrome in Finland is caused by 2 specific NPHS 1 mutations, Fin major (the deletion of nucleotides 121-122 leading to a frameshift) and Fin minor (encoding a premature termination signal at amino acid 1109). ${ }^{12}$ A growing list of disease-associated mutations includes missense, splicing, and truncation mutations. ${ }^{20-23}$ Some nephrin mutations have been shown to cause defective trafficking of the protein. ${ }^{24}$ In addition to the high prevalence in Finland, NPHS1 mutations are frequent in Mennonites from Lancaster County, Pennsylvania. ${ }^{25}$ Eight percent of the Groffdale Conference Mennonites carry a specific altered NPHS1 allele. The incidence of CNF is 1 in 500 live births in this group.

The identification of NPHS1 has improved the antenatal diagnosis of CNF. Prenatal proteinuria and elevated $\alpha$-fetoprotein levels are observed in fetuses both heterozygous and homozygous for NPHS1 defects, making $\alpha$-fetoprotein levels a poor screening tool. ${ }^{26}$ In Finland, where 2 mutations account for $95 \%$ of disease, testing for these 2 alleles can provide an inexpensive and highly sensitive screen.

Mice homozygous for targeted disruption of nephrin have neonatal nephrosis. ${ }^{27-29}$ Nephrin knockout mice initially have normal-appearing podocytes, despite abnormal appearing slit-diaphragms, suggesting that nephrin's primary role in the kidney is in slit diaphragm function rather than in podocyte development. ${ }^{29}$

\section{RECESSIVE FSGS}

Fuchshuber et $\mathrm{al}^{30}$ described a form of nephrosis characterized by recessive transmission, early onset, resistance to steroid therapy, and rapid progression to end-stage kidney failure. The majority of the affected children showed an FSGS pattern on renal biopsy examination, though some showed MCD. The gene for this recessive form of FSGS was mapped to chromosome 1q25-31 and subsequently cloned. ${ }^{30,31}$ NPHS2, the responsible gene, encodes podocin, a 383 amino acid integral membrane protein. Podocin is homologous to stomatin family proteins and to MEC-2, part of the Caenorhabditis elegans mechanosensing apparatus. ${ }^{32}$ Podocin localizes to the slit-diaphragm and has been shown to interact directly with nephrin. ${ }^{17,18,33,34}$

The relatively small number of NPHS2 exons (8) facilitates mutational analysis of human DNA. Several recent reports have helped define the spectrum of NPHS2-associated disease. Many of the disease-associated mutations create truncated proteins, suggesting that disease results from a loss of function of NPHS2. ${ }^{35-39}$ Most affected individuals in these reports presented with disease in early childhood. R138Q appears to be a common disease-causing variant, and has been observed in several families without recent common ancestors. R138X seems to be particularly common in ArabIsraeli children with steroid-resistant nephrosis. ${ }^{35}$ Our data suggests that an R229Q variant, common in the general population, can cause late-onset FSGS when it occurs together with a second mutant (and probably more severe) allele. Podocin mutations underlie disease in a sizable fraction of both familial and nonfamilial instances of childhood-onset recessive FSGS. Fuchshuber et al ${ }^{36}$ found NPHS2 mutations in $46 \%$ of such families. Other studies suggest that NPHS2 mutations cause disease in $20 \%$ to $30 \%$ of children with sporadic steroid-resistant nephrotic syndrome. ${ }^{39,40}$

Recent reports suggests a podocin-nephrin interaction at a protein-protein and at a genetic level. Direct physical interactions between the proteins have been shown. ${ }^{17,18}$ Human data also suggest a genetic interaction. Koziell et $\mathrm{al}^{22}$ have reported that the presence of a single NPHS2 may modify 
the course of NPHS1-associated congenital nephrosis.

Recessive and steroid-resistant nephrotic syndrome (NS) is genetically heterogeneous. Fuchshuber et al identified one large family unlinked to the chromosome 1q locus in their report of locus identification. ${ }^{30}$ Our unpublished data also suggests heterogeneity in recessive disease. Genetic heterogeneity in human disease is not surprising, given the existence of several recessive loci for NS in mice.

\section{DOMINANT FSGS}

Autosomal-dominant forms of FSGS typically present later and are more slowly progressive than recessive forms. ${ }^{41-43}$ Mutations in ACTN4, encoding $\alpha$-actinin- 4 , cause a slowly progressive form of disease with dominant inheritance, nonnephrotic proteinuria, and renal insufficiency. ${ }^{44}$ The penetrance of ACTN4-associated disease is high but not $100 \%$ : in these families, several individuals carry disease-associated mutations but have no proteinuria or renal insufficiency.

ACTN4 is one of $4 \alpha$-actinin genes. These genes encode biochemically similar, highly homologous proteins. The $\alpha$-actinins form approximately $100-k d$ head-to-tail homodimers. ACTN4 is the only actinin expressed significantly in the human glomerulus. ${ }^{44}$ The ACTN4 mutations identified in FSGS families are all missense and increase the affinity of the encoded protein to actin filaments. ${ }^{44}$ $\alpha$-actinin/actin affinity affects mechanical properties of actin gels, suggesting that these mutations may alter the mechanical properties of the podocyte. ${ }^{45}$ This form of disease appears to be rare compared with NPHS1- and NPHS2-associated nephrosis.

ACTN4 mutations appear to explain only a fraction of dominant FSGS. Another locus on chromosome $11 \mathrm{q}$ has been reported. ${ }^{46}$ Most families do not show evidence of linkage to either the chromosome 19q13 (ACTN4) or this 11q locus. It remains unknown whether disease in most of these families is caused by inherited podocyte defects.

\section{SYNDROMIC FSGS}

FSGS and related podocyte disorders also are seen as part of well-defined inherited syndromes. The spectrum of disease seen with WT1 mutations is the best studied of these disorders. The WT1 transcription factor was cloned on the basis of its role in the development of Wilms tumor. ${ }^{47,48}$ Frasier syndrome and Denys-Drash syndrome are related and overlapping syndromes caused by mutations in WT1. ${ }^{49-52}$ Both syndromes are characterized by glomerular disease and the development of male pseudohermaphroditism. Frasier syndrome is caused by donor splice mutations in intron 9 of WT1. An FSGS pattern is seen on renal biopsy examination. Frasier syndrome can present as FSGS in 46,XX females in association with gonadal malignancy. ${ }^{53,54}$ WT1 mutations are not a significant cause of glomerular disease in the absence of other genitourinary features. ${ }^{55}$ DenysDrash syndrome is defined by diffuse mesangial sclerosis on renal biopsy examination, genitourinary tumors, and pseudohermaphroditism. A different spectrum of mutations is seen in DenysDrash syndrome, most commonly within exon 9 of WT1. ${ }^{49,56}$

Nail-Patella syndrome generally is regarded as a disease of the basement membrane rather than the podocyte, though it is probably both. Affected individuals typically show nephropathy, as well as dysplastic nails, and absent or hypoplastic patellae. An altered glomerular basement membrane typically predominates on histologic analysis, the glomerulopathy is variable and can present as nephrotic syndrome. ${ }^{57}$ Defects in the $1 m x 1 b$ transcription factor are responsible for disease. ${ }^{58,59}$ Lmx $1 b$ helps control the transcriptional regulation of matrix proteins by the podocyte as well as the podocyte genes CD2AP and NPHS2. ${ }^{60-63}$ A variety of other inherited syndromes are associated with an increased frequency of FSGS. For example, Charcot-Marie Tooth disease and Galloway-Mowat syndrome are both inherited neuropathies in which nephrosis and/or FSGS are seen with increased frequency. ${ }^{64,65}$

\section{SECONDARY FSGS}

The role of human FSGS and NS genes in acquired disease is a subject of ongoing investigation. Some studies have reported increased nephrin expression in animal models of disease, others have reported decreased expression in other models. ${ }^{66-70}$ Results from human studies have not yet provided a clear picture of the nature and role of nephrin expression in acquired glomerulopathies. ${ }^{71,72}$ 


\section{CLINICAL SPECTRUM OF DISEASE}

Different defects in the podocyte lead to different clinical presentations. Further elucidation of the molecular mechanisms of these diseases are required to fully understand these differences.

Disease caused by defects in NPHS1, NPHS2, and ACTN4 forms a spectrum from prenatal-onset, to childhood-onset, to adult-onset disease. In addition, the disease severity caused by defects in any one of these genes is quite variable as well. It is unclear if the difference between FSGS and NS genes has to do simply with the severity of the resulting podocyte defect, or if FSGS genes perturb a different biologic pathway than NS genes. Interestingly, one recent report observed that patients with 2 defective NPHS1 alleles and a third mutation in NPHS2 showed a congenital FSGS phenotype. ${ }^{22}$ Some genes (such as NPHS1) may encode proteins whose major (or sole) function is to maintain the glomerular filtration barrier, whereas others encode proteins that function primarily to establish or maintain the normal podocyte architecture (such as ACTN4). Defects in genes that alter the filtration barrier also may alter the podocyte's production of glomerular basement membrane matrix proteins, leading to variations in glomerulosclerosis.

\section{SPORADIC FSGS}

What causes most cases of FSGS and MCD? A significant fraction of sporadic FSGS in children is caused by NPHS2 mutations. However, a greater fraction still remain unexplained by defects in known genes. Likely, complex combinations of genetic and environmental factors contribute to the development of much of this disease. For example, it has been suggested that parvovirus infection is associated with the development of FSGS. ${ }^{73,74} \mathrm{Hu}-$ man immunodeficiency virus infection also is associated with an FSGS-like lesion. ${ }^{75}$ Although purely speculative, it may be the case that some moderately frequent variants in podocyte proteins alter the response of these cells to an altered T-cell repertoire.

\section{IMPLICATIONS}

Prenatal and presymptomatic diagnosis is possible for inherited diseases with known genetic bases. The practical value of such testing depends on the specifics of the disease. As noted earlier, prenatal testing for specific identification of CNFassociated NPHS1 alleles already has been shown to be a useful clinical tool. The use of NPHS2 testing to determine response to treatment still needs to be verified. The value of genetic testing for other forms of FSGS or NS will depend on the frequency of these forms of disease and their implications for response to specific treatments. At present, genetic testing for FSGS and NS genes remains primarily a research tool, rather than a clinical test. In the next several years, testing for at least some of these genes likely will evolve into useful clinical tools. As with other forms of inherited kidney disease, care must be taken to avoid using an affected relative as a renal transplant donor. Because the familial pattern of inheritance may not always be obvious in inherited FSGS, clinicians should take particular care. As a practical matter, at the present time, the best method for ensuring this is to be certain that the potential donor has absolutely no microalbuminuria in multiple repeated measurements.

Does the human variation in the renal response to primary insults (such as diabetes, hypertension, reflux) involve common differences in genes that regulate podocyte structure and function? Variations in some genes may be involved in the heritable response to podocyte injury, whereas other variations may cause altered podocyte function directly. Progress in the genetic and biologic understanding of inherited podocytopathies will continue. Ultimately, we may come to regard much of the NS/FSGS group of diseases as a collection of inherited defects in the podocyte, the immune system, and genes involved in the response to injury.

\section{REFERENCES}

1. Werner M: Handbuch der Erbbiologie. 1942

2. Vernier RL, Brunson J, Good RA: Studies on familial nephrosis. J Dis Child 93:469, 1957

3. Die konstitutionelle bereitschaft zum nephrosesyndrome. Helv Paediatr Acta 6:199-218, 1951

4. Tejani A, Nicastri A, Phadke K, et al: Familial focal segmental glomerulosclerosis. Int J Pediatr Nephrol 4:231-234, 1983

5. Conlon PJ, Butterly D, Albers F, et al: Clinical and pathologic features of familial focal segmental glomerulosclerosis. Am J Kidney Dis 26:34-40, 1995

6. Moncrieff MW, White RH, Glasgow EF, et al: The familial nephrotic syndrome. II. A clinicopathological study. Clin Nephrol 1:220-229, 1973

7. Mehls O, Scharer K: Familial nephrotic syndrome. Monatsschr Kinderheilkd 118:328-330, 1970

8. Faubert PF, Porush JG: Familial focal segmental glomer- 
ulosclerosis: Nine cases in four families and review of the literature. Am J Kidney Dis 30:265-270, 1997

9. Rapola J: Congenital nephrotic syndrome. Pediatr Nephrol 1:441-446, 1987

10. Srivastava T, Whiting JM, Garola RE, et al: Podocyte proteins in Galloway-Mowat syndrome. Pediatr Nephrol 16: 1022-1029, 2001

11. Mannikko M, Kestila M, Holmberg C, et al: Fine mapping and haplotype analysis of the locus for congenital nephrotic syndrome on chromosome 19q13.1. Am J Hum Genet 57:1377-1383, 1995

12. Kestila M, Lenkerri U, Mannikko M, et al: Positionally cloned gene for a novel glomerular protein-nephrin-is mutated in congenital nephrotic syndrome. Mol Cell 1:575-582, 1998

13. Lenkkeri U, Mannikko M, McCready P, et al: Structure of the gene for congenital nephrotic syndrome of the Finnish type (NPHS1) and characterization of mutations. Am J Hum Genet 64:51-61, 1999

14. Holzman LB, St. John PL, Kovari IA, et al: Nephrin localizes to the slit pore of the glomerular epithelial cell. Kidney Int 56:1481-1491, 1999

15. Holthofer H, Ahola H, Solin ML, et al: Nephrin localizes at the podocyte filtration slit area and is characteristically spliced in the human kidney. Am J Pathol 155:1681-1687, 1999

16. Ruotsalainen V, Ljungberg P, Wartiovaara J, et al: Nephrin is specifically located at the slit diaphragm of glomerular podocytes. Proc Natl Acad Sci U S A 96:7962-7967, 1999

17. Schwarz K, Simons M, Reiser J, et al: Podocin, a raftassociated component of the glomerular slit diaphragm, interacts with CD2AP and nephrin. J Clin Invest 108:1621-1629, 2001

18. Huber TB, Kottgen M, Schilling B, et al: Interaction with podocin facilitates nephrin signaling. J Biol Chem 276:4154341546, 2001

19. Simons M, Schwarz K, Kriz W, et al: Involvement of lipid rafts in nephrin phosphorylation and organization of the glomerular slit diaphragm. Am J Pathol 159:1069-1077, 2001

20. Patrakka J, Kestila M, Wartiovaara J, et al: Congenital nephrotic syndrome (NPHS1): Features resulting from different mutations in Finnish patients [In Process Citation]. Kidney Int 58:972-980, 2000

21. Beltcheva O, Martin P, Lenkkeri U, et al: Mutation spectrum in the nephrin gene (NPHS1) in congenital nephrotic syndrome. Hum Mutat 17:368-373, 2001

22. Koziell A, Grech V, Hussain S, et al: Genotype/phenotype correlations of NPHS1 and NPHS2 mutations in nephrotic syndrome advocate a functional inter-relationship in glomerular filtration. Hum Mol Genet 11:379-388, 2002

23. Aya K, Tanaka H, Seino Y: Novel mutation in the nephrin gene of a Japanese patient with congenital nephrotic syndrome of the Finnish type. Kidney Int 57:401-404, 2000

24. Liu L, Done SC, Khoshnoodi J, et al: Defective nephrin trafficking caused by missense mutations in the NPHS1 gene: Insight into the mechanisms of congenital nephrotic syndrome. Hum Mol Genet 10:2637-2644, 2001

25. Bolk S, Puffenberger EG, Hudson J, et al: Elevated frequency and allelic heterogeneity of congenital nephrotic syndrome, Finnish type, in the old order Mennonites. Am J Hum Genet 65:1785-1790, 1999

26. Patrakka J, Martin P, Salonen R, et al: Proteinuria and prenatal diagnosis of congenital nephrosis in fetal carriers of nephrin gene mutations. Lancet 359:1575-1577, 2002

27. Rantanen M, Palmen T, Patari A, et al: Nephrin TRAP mice lack slit diaphragms and show fibrotic glomeruli and cystic tubular lesions. J Am Soc Nephrol 13:1586-1594, 2002

28. Putaala H, Soininen R, Kilpelainen P, et al: The murine nephrin gene is specifically expressed in kidney, brain and pancreas: Inactivation of the gene leads to massive proteinuria and neonatal death. Hum Mol Genet 10:1-8, 2001

29. Hamano Y, Grunkemeyer JA, Sudhakar A, et al: Determinants of vascular permeability in the kidney glomerulus. J Biol Chem 277:31154-31162, 2002

30. Fuchshuber A, Jean G, Gribouval O, et al: Mapping a gene (SRN1) to chromosome 1q25-q31 in idiopathic nephrotic syndrome confirms a distinct entity of autosomal recessive nephrosis. Hum Mol Genet 4:2155-2158, 1995

31. Boute N, Gribouval O, Roselli S, et al: NPHS2, encoding the glomerular protein podocin, is mutated in autosomal recessive steroid-resistant nephrotic syndrome. Nat Genet 24:349354,2000

32. Huang M, Gu G, Ferguson EL, et al: A stomatin-like protein necessary for mechanosensation in C. elegans. Nature 378:292-295, 1995

33. Roselli S, Gribouval O, Boute N, et al: Podocin localizes in the kidney to the slit diaphragm area. Am J Pathol 160:131139, 2002

34. Palmen T, Lehtonen S, Ora A, et al: Interaction of endogenous nephrin and CD2-associated protein in mouse epithelial M-1 cell line. J Am Soc Nephrol 13:1766-1772, 2002

35. Frishberg Y, Rinat C, Megged O, et al: Mutations in NPHS2 encoding podocin are a prevalent cause of steroidresistant nephrotic syndrome among Israeli-Arab children. J Am Soc Nephrol 13:400-405, 2002

36. Fuchshuber A, Gribouval O, Ronner V, et al: Clinical and genetic evaluation of familial steroid-responsive nephrotic syndrome in childhood. J Am Soc Nephrol 12:374-378, 2001

37. Wu MC, Wu JY, Lee CC, et al: A novel polymorphism $(c 288 \mathrm{C}>\mathrm{T})$ of the NPHS2 gene identified in a Taiwan Chinese family. Hum Mutat 17:81-82, 2001

38. Wu MC, Wu JY, Lee CC, et al:. Two novel polymorphisms (c954T $>\mathrm{C}$ and c1038A $>\mathrm{G}$ ) in exon 8 of NPHS2 gene identified in Taiwan Chinese. Hum Mutat 17:237, 2001

39. Caridi G, Bertelli R, Carrea A, et al: Prevalence, genetics, and clinical features of patients carrying podocin mutations in steroid-resistant nonfamilial focal segmental glomerulosclerosis. J Am Soc Nephrol 12:2742-2746, 2001

40. Karle SM, Uetz B, Ronner V, et al: Novel mutations in NPHS2 detected in both familial and sporadic steroid-resistant nephrotic syndrome. J Am Soc Nephrol 13:388-393, 2002

41. Conlon PJ, Lynn K, Winn MP, et al: Spectrum of disease in familial focal and segmental glomerulosclerosis. Kidney Int 56:1863-1871, 1999

42. Mathis BJ, Kim SH, Calabrese K, et al: A locus for inherited focal segmental glomerulosclerosis maps to chromosome 19q13: Rapid communication. Kidney Int 53:282-286, 1998

43. Vats A, Nayak A, Ellis D, et al: Familial nephrotic syndrome: Clinical spectrum and linkage to chromosome 19q13. Kidney Int 57:875-881, 2000

44. Kaplan JM, Kim SH, North KN, et al: Mutations in 
ACTN4, encoding $\alpha$-actinin-4, cause familial focal segmental glomerulosclerosis. Nat Genet 24:251-256, 2000

45. Wachsstock DH, Schwartz WH, Pollard TD: Affinity of $\alpha$-actinin for actin determines the structure and mechanical properties of actin filament gels. Biophys J 65:205-214, 1993

46. Winn MP, Conlon PJ, Lynn KL, et al: Linkage of a gene causing familial focal segmental glomerulosclerosis to chromosome 11 and further evidence of genetic heterogeneity. Genomics 58:113-120, 1999

47. Haber DA, Buckler AJ, Glaser T, et al: An internal deletion within an $11 \mathrm{p} 13$ zinc finger gene contributes to the development of Wilms' tumor. Cell 61:1257-1269, 1990

48. Gessler M, Poustka A, Cavenee W, et al: Homozygous deletion in Wilms tumours of a zinc-finger gene identified by chromosome jumping. Nature 343:774-778, 1990

49. Pelletier J, Bruening W, Kashtan CE, et al: Germline mutations in the Wilms' tumor suppressor gene are associated with abnormal urogenital development in Denys-Drash syndrome. Cell 67:437-447, 1991

50. McTaggart SJ, Algar E, Chow CW, et al: Clinical spectrum of Denys-Drash and Frasier syndrome. Pediatr Nephrol 16:335-339, 2001

51. Barbaux S, Niaudet P, Gubler MC, et al: Donor splicesite mutations in WT1 are responsible for Frasier syndrome. Nat Genet 17:467-470, 1997

52. Klamt B, Koziell A, Poulat F, et al: Frasier syndrome is caused by defective alternative splicing of WT1 leading to an altered ratio of WT1 \pm KTS splice isoforms. Hum Mol Genet 7:709-714, 1998

53. Demmer L, Primack W, Loik V, et al: Frasier syndrome: A cause of focal segmental glomerulosclerosis in a $46, \mathrm{XX}$ female. J Am Soc Nephrol 10:2215-2218, 1999

54. Denamur E, Bocquet N, Mougenot B, et al: Mother-tochild transmitted WT1 splice-site mutation is responsible for distinct glomerular diseases. J Am Soc Nephrol 10:2219-2223, 1999

55. Denamur E, Bocquet N, Baudouin V, et al: WT1 splicesite mutations are rarely associated with primary steroid-resistant focal and segmental glomerulosclerosis. Kidney Int 57: 1868-1872, 2000

56. Schumacher V, Scharer K, Wuhl E, et al: Spectrum of early onset nephrotic syndrome associated with WT1 missense mutations. Kidney Int 53:1594-1600, 1998

57. Simila S, Vesa L, Wasz-Hockert O: Hereditary onychoosteodysplasia (the nail-patella syndrome) with nephrosis-like renal disease in a newborn boy. Pediatrics 46:61-65, 1970

58. Dreyer SD, Zhou G, Baldini A, et al: Mutations in LMX1B cause abnormal skeletal patterning and renal dysplasia in nail patella syndrome. Nat Genet 19:47-50, 1998

59. Chen H, Lun Y, Ovchinnikov D, et al: Limb and kidney defects in Lmx1b mutant mice suggest an involvement of LMX1B in human nail patella syndrome. Nat Genet 19:51-55, 1998
60. Morello R, Zhou G, Dreyer SD, et al: Regulation of glomerular basement membrane collagen expression by LMX1B contributes to renal disease in nail patella syndrome. Nat Genet 27:205-208, 2001

61. Morello R, Lee B: Insight into podocyte differentiation from the study of human genetic disease: Nail-patella syndrome and transcriptional regulation in podocytes. Pediatr Res 51:551558,2002

62. Miner JH, Morello R, Andrews KL, et al: Transcriptional induction of slit diaphragm genes by $\mathrm{Lmx} 1 \mathrm{~b}$ is required in podocyte differentiation. J Clin Invest 109:1065-1072, 2002

63. Rohr C, Prestel J, Heidet L, et al: The LIM-homeodomain transcription factor Lmx $1 \mathrm{~b}$ plays a crucial role in podocytes. J Clin Invest 109:1073-1082, 2002

64. Chance PF, Fishbeck KJ: Molecular genetics of CharcotMarie-tooth disease and related neuropathies. Hum Mol Genet 3:1503-1507, 1994

65. Cohen AH, Turner MC: Kidney in Galloway-Mowat syndrome: Clinical spectrum with description of pathology. Kidney Int 45:1407-1415, 1994

66. Luimula P, Ahola H, Wang SX, et al: Nephrin in experimental glomerular disease. Kidney Int 58:1461-1468, 2000

67. Luimula P, Sandstrom N, Novikov D, et al: Podocyteassociated molecules in puromycin aminonucleoside nephrosis of the rat. Lab Invest 82:713-718, 2002

68. Yuan H, Takeuchi E, Taylor GA, et al: Nephrin dissociates from actin, and its expression is reduced in early experimental membranous nephropathy. J Am Soc Nephrol 13:946956, 2002

69. Bonnet F, Tikellis C, Kawachi H, et al: Nephrin expression in the post-natal developing kidney in normotensive and hypertensive rats. Clin Exp Hypertens 24:371-381, 2002

70. Bonnet F, Cooper ME, Kawachi H, et al: Irbesartan normalises the deficiency in glomerular nephrin expression in a model of diabetes and hypertension. Diabetologia 44:874-877, 2001

71. Patrakka J, Ruotsalainen V, Ketola I, et al: Expression of nephrin in pediatric kidney diseases. J Am Soc Nephrol 12:289296, 2001

72. Doublier S, Ruotsalainen V, Salvidio G, et al: Nephrin redistribution on podocytes is a potential mechanism for proteinuria in patients with primary acquired nephrotic syndrome. Am J Pathol 158:1723-1731, 2001

73. Tanawattanacharoen S, Falk RJ, Jennette JC, et al: Parvovirus B19 DNA in kidney tissue of patients with focal segmental glomerulosclerosis. Am J Kidney Dis 35:1166-1174, 2000

74. Moudgil A, Nast CC, Bagga A, et al: Association of parvovirus B19 infection with idiopathic collapsing glomerulopathy. Kidney Int 59:2126-2133, 2001

75. Klotman PE: HIV-associated nephropathy. Kidney Int 56:1161-1176, 1999 